\title{
Growth Forecasts, Belief Manipulation and Capital Markets*
}

\author{
Patrick Leoni ${ }^{\dagger} \quad$ Frederik Lundtofte ${ }^{\ddagger}$
}

December, 2010

\begin{abstract}
We analyze how a benevolent government agency would optimally release information about the growth rate of the stochastic dividend process of the financial market. We investigate the effects of the agency's signal on the agents' optimal strategies and equilibrium asset prices. In the case where all investors are rational Bayesian updaters, we show that the agency's optimal choice is to release a manipulative signal (lie) with probability one. However, if there are some nonupdating (inattentive) agents, we find cases where it is optimal for the government agency to send a revealing signal with probability one.
\end{abstract}

Keywords: Social welfare, information, forecasting, asset pricing, inattention

JEL codes: D8, G11, G12

${ }^{*}$ We would like to thank D. Feldman, H. J. Holm, Y. Lengwiler, G. Nöldeke and seminar participants at Durham Business School, Basel U., the XI JOLATE, the Singapore MDSS and the 2010 RES meetings for helpful comments. Frederik Lundtofte gratefully acknowledges financial support from the Jan Wallander and Tom Hedelius Foundation (grants W2005-0365:1 and P2009-0053:1) and Lund Institute of Economic Research.

${ }^{\dagger}$ EUROMED Management, Domaine de Luminy - BP 921, F-13 288 Marseille Cedex 9, France. Phone: +33 491827 749. E-mail: patrick.leoni@euromed-management.com

${ }^{\ddagger}$ Department of Economics, Lund University, P.O. Box 7082, S-220 07 Lund, Sweden. Phone: +46 46 222 8670. Fax: +46 46222 4118. E-mail: frederik.lundtofte@nek.lu.se 


\section{Introduction}

The credibility of governments, when dealing with financial markets, is at the very heart of most economic policies. The latest, and perhaps most striking example was in 2008, when the US government attempted to launch its bailout policy towards major industries on the brink of bankruptcy. Most opponents argued that this bailout policy came down to passing the bucket to taxpayers, whereas the government tried to convince economic agents that the capital used in those operations was mere loans to be repaid when times get better. Needless to say, the main task of the government at the time it tried to pass the bill was to convince markets and congressmen that better times will very soon be ahead, so that the opportunity cost of the bailout would be acceptable.

This example extends to many other economic situations, such as inflation target and unemployment rates announcements for instance, where the government or the local central bank may seek to induce optimistic beliefs in financial markets. The point may not be to trigger speculative bubbles, but rather to prevent investors from precautionary measures leading them to withdraw capital from those markets. This way, enough liquidity remains available in financial markets and worse scenarios, such as systemic risk of widespread banking failures (as happened in 2009), are prevented. From the point of view of social welfare, is it not better that investors remain unaware of bad times ahead? Is it even socially desirable to publicly announce forecasts of upcoming recessions?

One can easily anticipate that actual forecasts from official bodies with ties to the government would be overly optimistic, particularly right before elections. Indeed, there 
is ample empirical evidence confirming this assertion. Jonung and Larch (2006) find a significant upward bias in government forecasts of both real and potential GDP growth in Germany, Italy and France. Similarly, Ashiya (2007) finds a significant upward bias in the official government forecasts of real GDP growth in Japan. Boylan (2008) demonstrates that forecasts of state revenues in the US tend to be overly optimistic right before and right after gubernatorial elections, and he argues that this is due to a political incentive to satisfy a balanced budget requirement and avoid raising taxes. More specifically, he finds that, in gubernatorial election years, budget officials overstate the growth in state and US personal income.

Given this background, we analyze from a theoretical viewpoint how a benevolent government agency would choose to release information regarding future growth rates and its effects on asset prices in an exchange-only Lucas (1978) economy. For simplicity, we model three dates, but our results readily extend to more general settings (e.g., repeated interaction under IID growth rates and "stationary" updating rules). The government agency chooses between releasing a (partially) revealing signal and releasing a manipulative signal (lying), according to which the future growth rate is always high regardless of the true future growth rate. We show that, with rational Bayesian investors with homogeneous beliefs, the government agency, seeking to maximize social welfare, will always choose to release the lie.

The intuition is that, upon observing a signal regarding low future growth, agents will conclude that the signal must have been revealing, and so the future growth is most likely to be low. It turns out that this belief lowers their expected utility. Given any 
consumer beliefs regarding the probability that a signal is revealing, it is thus optimal for the government agency to release a manipulative signal (lie) about a high growth rate.

Bayesian rationality is at the heart of the result, and we find other forms of rationality with empirical support where the government finds it optimal to always release a revealing signal. The finance literature finds evidence of investors' underreaction to news, otherwise known as inattention (e.g., Huberman and Regev 2001, DellaVigna and Pollet 2006, Cohen and Frazzini 2008, Hirshleifer, Lim, and Teoh 2009). Accordingly, we extend the model to include a group of agents who do not update their beliefs after observing the government agency's signal. In this case, the updating agents can use the information contained in the public signal as they trade with the nonupdating agents. They behave in a way that is similar to the investor who obtains the signal as private information: it is no longer optimal for them just to consume the dividends from their endowed stock. Instead, they want to trade on the information present in the government agency's signal. It turns out that, in this case, the government agency's optimal strategy can be the opposite of what was obtained assuming all agents were updating. That is, in this case, it can instead be optimal for the government agency to release the revealing signal with probability one. Hence, when there are both updating and nonupdating agents, where the former trade on the information contained in the government agency's signal, the revealing signal can be of higher social value than the manipulative one. In the words of Jack Hirshleifer "Information is of value only if it can affect action" (Hirshleifer 1971, p. 564).

The paper is related to the literature on the social value of public information. Drèze (1960) and Hirshleifer (1971) identify the possibility that information may have a negative 
social value, which became known as the "Hirshleifer effect." Since then, several authors have investigated the robustness of this result (e.g., Marshall 1974, Ng 1975, Green 1981, Hakansson, Kunkel, and Ohlson 1982, Schlee 2001, Campbell 2004). In the context of a "beauty contest" à la Keynes (1936), Morris and Shin (2002) show that greater provision of public information may not improve welfare. This result has gained attention in the media (Economist 2004) and spurred academic debate (Svensson 2006, Morris, Shin, and Tong 2006). We contribute to this literature mainly by showing how the presence of some inattentive agents may cause a welfare-maximizing government agency to send a revealing signal.

Another branch of the literature to which we contribute is that of signaling games, starting with the seminal works of Spence (1973) and Riley (1975) 11 In the Spence/Riley framework, costs and attributes are exogenously modeled to be one to one. Thus, in Spence/Riley signaling equilibria, separation by costs automatically implies separation by attributes and no manipulation is possible $2^{2}$ Crawford and Sobel (1982) explicitly model the choice to manipulate and allow it to be endogenously optimally chosen. They consider a better-informed sender who sends a signal to a receiver who then takes an action that affects the welfare of both. A central result in Crawford and Sobel (1982) is that "the

\footnotetext{
${ }^{1}$ See Riley (2001) for an excellent overview of this literature.

${ }^{2}$ The contributions by Feldman (2004) and Feldman and Winer (2004) allow for a general relation between costs and attributes: All attributes (discrete and continuous) are (randomly) associated with all costs (on a continuum). They establish conditions for separating-by-costs equilibria, as full separation by attributes is (obviously) impossible. In their equilibria, different signal levels (sent, each, by all levels of attributes) induce different lotteries over attributes.
} 
more similar agents' preferences, the more informative the equilibrium signal" (Crawford and Sobel 1982, p. 1432). We contrast these results by showing - in a related frameworkthat, even though the sender's (i.e., the government agency's) utility is completely aligned with that of the receivers, the sender still chooses to manipulate.

In spite of the fact that, in the benchmark model where all agents are updating, social welfare is decreasing in the probability that the government agency releases a revealing signal as public information, the revealing signal has a substantial value if it becomes private information. That is, if everyone except one individual receives the manipulative signal and this one individual receives the revealing signal as private information, then this individual, knowing that he has received a revealing signal, can benefit by trading with the less-informed agents. We analyze the privately informed agent's optimal trading strategies, consumption and his gains in terms of certainty-equivalent wealth. Our results indicate that the gains of receiving the revealing signal in terms of certainty-equivalent wealth are substantial for almost all levels of risk aversion, with most values being in the range from $20 \%$ to $40 \%$ of the initial dividend value. This last result is consistent with Theorem 1, p. 97 in Laffont (1991), which shows that a von Neumann-Morgenstern utility maximizer is always ex-ante better off whenever her information set is coarser.

The paper is organized as follows. In Section 2, we introduce the benchmark model. Section 3 presents the theoretical results with updating agents. In Section 4, we give cases where truth-telling may become optimal with inattentive agents. The fifth section concludes the paper. The discussion of the private value of information, together with some technical proofs, are given in the appendix. 


\section{Benchmark model}

We consider a three-date, exchange-only Lucas (1978) economy. In this economy, there is a continuum of atomless agents with a total mass of one, who are price takers, and a government agency. There is one consumption good and two assets: a risk-free asset yielding one unit of consumption good at the last date $t=3$, and a risky asset (stock) whose return at $t=3$ depends on one of the two realizations of nature (high $\mathrm{h}$, or low l) as follows. The risky asset returns a known dividend, $D_{2}$, at date $t=2$ and a second dividend, $\widetilde{D}_{3}=D_{2} g$, at the final date, $t=3$, where, for simplicity, $g$ is a binary random variable, described below. Without loss of generality, we assume that the ownership of the risky asset is uniformly distributed across the agents; this ownership is their sole endowment.

At date $t=1$, the realization of the random variable $g$ is not yet known. The agents and the government agency share a common prior regarding the future growth rate $g$, according to which this growth rate is high $\left(g=g_{\mathrm{h}}\right)$ with probability $p_{\mathrm{h}}$ and $l o w\left(g=g_{\mathrm{l}}\right)$ with probability $1-p_{\mathrm{h}}$. That is,

$$
g=\left\{\begin{array}{l}
g_{\mathrm{h}} \text { with probability } p_{\mathrm{h}} \\
g_{\mathrm{l}} \text { with probability } 1-p_{\mathrm{h}}
\end{array}\right.
$$

where $p_{\mathrm{h}} \in(0,1)$ and $0<g_{\mathrm{l}}<g_{\mathrm{h}}$.

At $t=1$, the government agency decides either to investigate (at zero cost for simplicity) the true growth rate $g$, or to deceive the public (at zero cost for simplicity) and send a high signal in the beginning of the following period without doing any research. 
If an investigation is initiated, a revealing signal, $s_{R}$, will be sent in the beginning of the next period. This signal returns the correct growth rate with probability $\xi \in\left(\frac{1}{2}, 1\right)$ and an incorrect growth rate with probability $1-\xi$. Formally, we have $\biguplus^{3}$

$$
s_{R}=\left\{\begin{array}{l}
g \text { with probability } \xi \\
\neg g \text { with probability } 1-\xi
\end{array}\right.
$$

where $\xi \in\left(\frac{1}{2}, 1\right)$. The manipulative signal (lie), which we denote by $s_{M}$, just returns $g_{\mathrm{h}}$ with probability one: $s_{M}=g_{\mathrm{h}}$.

We say that the signal $s_{R}$ partially reveals the growth rate because the distribution of $s_{R}$ conditional on the growth rate depends on the growth rate. Similarly, $s_{M}$ does not reveal anything about the growth rate, because the distribution of $s_{M}$ conditional on the growth rate does not depend on the growth rate.

The government agency maximizes social welfare, as described below, by choosing the probability $\theta$ of sending a revealing signal to the investors. At date $t=1$, these investors assign a probability $\widehat{\theta}$ to the possibility that the government agency sends a revealing signal.

At $t=2$, the government sends the previously chosen signal. The agents update their beliefs about $g$ as a function of the received signal, as well as the probability of receiving a revealing signal, in a Bayesian manner. According to their newly formed beliefs, at date $t=2$ they allocate their current wealth between current consumption and the two assets yielding consumption at $t=3$.

Every agent is a standard von Neumann-Morgenstern expected-utility maximizer, as

\footnotetext{
${ }^{3}$ Here, " $\neg g$ " means "not g." That is, if $g=g_{\mathrm{h}}$, then $\neg g=g_{\mathrm{l}}$ and if $g=g_{\mathrm{l}}$, then $\neg g=g_{\mathrm{h}}$.
} 
of $t=2$, with an intertemporal discount factor $\beta \in(0,1)$; that is, agents seek to maximize

$$
u\left(C_{2}^{i}\right)+\beta E^{\widehat{P}}\left[u\left(\widetilde{C}_{3}^{i}\right) \mid s\right], i \in[0,1]
$$

where $C_{2}^{i}$ denotes agent $i$ 's initial consumption, $\widetilde{C}_{3}^{i}$ denotes his final state-contingent consumption, and $\widehat{P}$ is his probability measure. The elementary utility function $u$ is concave, strictly increasing, and twice-continuously differentiable. In addition, we assume that $u^{\prime}(c) \rightarrow+\infty$ as $c \rightarrow 0$. The agents' budget constraints are standard.

The objective of the government agency is to maximize social welfare from $t=1$ by choosing the appropriate signal to send while taking as given the individual demand functions and prices for which markets clear. In particular, the strategy for the agency is to choose the likelihood, $\theta$, of sending the revealing signal. Thus, the agency seeks to maximize the expression

$$
\mathcal{W}=E^{P}\left[\int_{[0,1]}\left(u\left(C_{2}^{i}\right)+\beta E^{\widehat{P}}\left[u\left(\widetilde{C}_{3}^{i}\right) \mid s\right]\right) \mathrm{d} i\right],
$$

over $\theta(0 \leq \theta \leq 1)$. Here, $P$ denotes the agency's probability measure (under which its strategy $\theta$ is known), and $C_{2}^{i}$ and $\widetilde{C}_{3}^{i}$ are the equilibrium consumption levels such that markets clear.

The structure of the signals, $g_{\mathrm{h}}, g_{\mathrm{l}}, p_{\mathrm{h}}, \xi$, the agents' preferences and beliefs and the government agency's objective function are common knowledge.

Formally, we consider the following equilibrium concept.

Definition 1 An equilibrium for the economy described above is a set of consumption and investment decisions $\left\{C_{2}^{i *}, \phi^{i *}\right\}_{i \in[0,1]}$, a government agency strategy $\theta^{*}$, a set of prices $(S, B)$ and a system of beliefs $\widehat{\operatorname{Pr}}\left(g=g_{\mathrm{h}} \mid s\right)$ such that 
i) $\left\{C_{2}^{i *}, \phi^{i *}\right\}_{i \in[0,1]}$ solve the agents' consumption and investment problems given $\widehat{\operatorname{Pr}}(g=$ $\left.g_{\mathrm{h}} \mid s\right), S$ and $B$

ii) $\theta^{*}$ solves the government agency's problem given $\widehat{\operatorname{Pr}}\left(g=g_{\mathrm{h}} \mid s\right)$;

iii) Markets clear, $\int_{0}^{1} C_{2}^{i *} \mathrm{~d} i=D_{2}$ and $\int_{0}^{1} \phi^{i *} \mathrm{~d} i=1$; and

iv) $\widehat{\operatorname{Pr}}\left(g=g_{\mathrm{h}} \mid s\right)$ is computed according to Bayes' rule whenever possible. If $\widehat{\theta}=0$, we let $\widehat{\operatorname{Pr}}\left(g=g_{\mathrm{h}} \mid s=g_{\mathrm{l}}\right)=\left.\frac{p_{\mathrm{h}}(1-\xi)}{p_{\mathrm{h}}(1-\xi)+\left(1-p_{\mathrm{h}}\right) \xi}\right|^{4}$

\section{$3 \quad$ Lying with updating investors}

In this section, we discuss why it is always optimal for the government to lie when dealing with rational Bayesian investors. In the following section, we consider a variation of the benchmark model where the presence of some inattentive (nonupdating) agents triggers truth-telling from the government.

\subsection{The agents' decision}

Letting $S$ be the ex-dividend price of the risky asset at the time of decision, letting $B$ denote the price of a bond yielding a payoff of one unit of consumption at the final date and letting $\phi^{i}$ be the number of stocks held by agent $i$, we have that agent $i$ 's consumption at the final date must equal his final wealth:

$$
\widetilde{C}_{3}^{i}=\phi^{i} \widetilde{D}_{3}+\left(\frac{S+D_{2}-\phi^{i} S-C_{2}^{i}}{B}\right) \cdot 1 .
$$

\footnotetext{
${ }^{4}$ Note that this is the limiting posterior as $\widehat{\theta} \rightarrow 0$ (see the proof of Lemma 2 in the appendix).
} 
Hence, agent $i$ 's problem can be written as

$$
\max _{C_{2}^{i}, \phi^{i}}\left\{u\left(C_{2}^{i}\right)+\beta E^{\widehat{P}}\left[u\left(\phi^{i} \widetilde{D}_{3}+\left(\frac{S+D_{2}-\phi^{i} S-C_{2}^{i}}{B}\right) \cdot 1\right) \mid s\right]\right\}
$$

s.t.

$$
\begin{aligned}
C_{2}^{i} & \geq 0 \\
\phi^{i} D_{2}\left(1+g_{\mathrm{h}}\right)+\left(\frac{S+D_{2}-\phi^{i} S-C_{2}^{i}}{B}\right) \cdot 1 & \geq 0 \\
\phi^{i} D_{2}\left(1+g_{\mathrm{l}}\right)+\left(\frac{S+D_{2}-\phi^{i} S-C_{2}^{i}}{B}\right) \cdot 1 & \geq 0
\end{aligned}
$$

However, since $u^{\prime}(c) \rightarrow+\infty$ as $c \rightarrow 0$, the constraints are not binding. Thus, the firstorder conditions are as follows.

$$
\begin{array}{ll}
C_{2}^{i}: & u^{\prime}\left(C_{2}^{i *}\right)-\frac{1}{B} \beta E^{\widehat{P}}\left[u^{\prime}\left(\widetilde{C}_{3}^{i *}\right) \mid s\right]=0 \\
\phi^{i}: & E^{\widehat{P}}\left[\left(\widetilde{D}_{3}-\frac{S}{B}\right) u^{\prime}\left(\widetilde{C}_{3}^{i *}\right) \mid s\right]=0 .
\end{array}
$$

Due to the concavity of the problem, the first-order conditions are sufficient for a maximum.

\subsection{Asset market equilibrium}

We now pin down the equilibrium prices of the assets, as a function of the signal sent and the resulting beliefs. From 10 , we have that the price of the bond is given by

$$
B=E^{\widehat{P}}\left[\frac{\beta u^{\prime}\left(\widetilde{C}_{3}^{i *}\right)}{u^{\prime}\left(C_{2}^{i *}\right)} \mid s\right] .
$$

Combining the above equation with (11), we obtain the price of the stock as

$$
S=E^{\widehat{P}}\left[\frac{\beta u^{\prime}\left(\widetilde{C}_{3}^{i *}\right)}{u^{\prime}\left(C_{2}^{i *}\right)} \widetilde{D}_{3} \mid s\right] .
$$


Since the agents share the same preferences, have access to the same information and face the same budget constraint (Eq. (5)), they will choose the same initial consumption and the same number of stocks: $C_{2}^{i *}=C_{2}^{*}$ and $\phi^{i *}=\phi^{*}$ for all $i$. From market clearing, we have that, in equilibrium, $C_{2}^{*}=D_{2}$ and $\phi^{*}=1$. By (5), this implies that $\widetilde{C}_{3}^{i *}=\widetilde{D}_{3}$. Hence, the stock and bond prices are given by

$$
S=E^{\widehat{P}}\left[\frac{\beta u^{\prime}\left(\widetilde{D}_{3}\right)}{u^{\prime}\left(D_{2}\right)} \widetilde{D}_{3} \mid s\right]
$$

and

$$
B=E^{\widehat{P}}\left[\frac{\beta u^{\prime}\left(\widetilde{D}_{3}\right)}{u^{\prime}\left(D_{2}\right)} \mid s\right] .
$$

\subsection{The government agency's decision}

It is straightforward to show that maximizing social welfare (4) with respect to the probability of a revealing signal $(\theta)$ is equivalent to maximizing the expected probability of a high growth rate:

Lemma 1 Maximizing the social welfare function in (4) with respect to $\theta$ is equivalent to maximizing $E^{P}\left[\widehat{\operatorname{Pr}}\left(g=g_{\mathrm{h}} \mid s\right)\right]$ with respect to $\theta$.

Proof. The objective function can be written as

$$
\begin{aligned}
E^{P}\left[u\left(D_{2}\right)+\beta\right. & \left.\left(\widehat{\operatorname{Pr}}\left(g=g_{\mathrm{h}} \mid s\right) u\left(D_{2} g_{\mathrm{h}}\right)+\left(1-\widehat{\operatorname{Pr}}\left(g=g_{\mathrm{h}} \mid s\right)\right) u\left(D_{2} g_{1}\right)\right)\right] \\
& =E^{P}\left[u\left(D_{2}\right)+\beta\left(u\left(D_{2} g_{1}\right)+\widehat{\operatorname{Pr}}\left(g=g_{\mathrm{h}} \mid s\right)\left(u\left(D_{2} g_{\mathrm{h}}\right)-u\left(D_{2} g_{1}\right)\right)\right)\right] .
\end{aligned}
$$

Since $\beta, u\left(D_{2}\right), u\left(D_{2} g_{\mathrm{h}}\right)$ and $u\left(D_{2} g_{\mathrm{l}}\right)$ do not depend on $\theta$, and $u\left(D_{2} g_{\mathrm{h}}\right)>u\left(D_{2} g_{\mathrm{l}}\right)$, maximizing the above expression with respect to $\theta$ is equivalent to maximizing $E^{P}[\widehat{\operatorname{Pr}}(g=$ 
$\left.\left.g_{\mathrm{h}} \mid s\right)\right]$ with respect to $\theta$.

The following lemma determines the agents' updated beliefs.

Lemma 2 The conditional probabilities $\widehat{\operatorname{Pr}}\left(g=g_{\mathrm{h}} \mid s=g_{\mathrm{h}}\right)$ and $\widehat{\operatorname{Pr}}\left(g=g_{\mathrm{h}} \mid s=g_{\mathrm{l}}\right)$ are given by

$$
\widehat{\operatorname{Pr}}\left(g=g_{\mathrm{h}} \mid s=g_{\mathrm{h}}\right)=\frac{p_{\mathrm{h}}(1-\widehat{\theta}(1-\xi))}{1-\widehat{\theta} \xi+p_{\mathrm{h}} \widehat{\theta}(2 \xi-1)}
$$

and

$$
\widehat{\operatorname{Pr}}\left(g=g_{\mathrm{h}} \mid s=g_{\mathrm{l}}\right)=\frac{p_{\mathrm{h}}(1-\xi)}{p_{\mathrm{h}}(1-\xi)+\left(1-p_{\mathrm{h}}\right) \xi} .
$$

See the appendix for a proof.

From the perspective of the government agency, who knows $\theta$, we have that

$$
\begin{aligned}
\operatorname{Pr}\left(s=g_{\mathrm{h}}\right) & =p_{\mathrm{h}} \theta \xi+\left(1-p_{\mathrm{h}}\right) \theta(1-\xi)+(1-\theta) \cdot 1 \\
& =1-\theta\left(\xi-p_{\mathrm{h}}(2 \xi-1)\right) .
\end{aligned}
$$

Thus, by virtue of Lemma 1, the government agency's problem can be rewritten as

$$
\begin{aligned}
\max _{0 \leq \theta \leq 1}\left(1-\theta\left(\xi-p_{\mathrm{h}}(2 \xi-1)\right)\right) \frac{p_{\mathrm{h}}(1-\widehat{\theta}(1-\xi))}{1-\widehat{\theta}\left(\xi-p_{\mathrm{h}}(2 \xi-1)\right)} & \\
& \quad+\theta\left(\xi+p_{\mathrm{h}}(2 \xi-1)\right) \frac{p_{\mathrm{h}}(1-\xi)}{p_{\mathrm{h}}(1-\xi)+\left(1-p_{\mathrm{h}}\right) \xi} .
\end{aligned}
$$

This problem is equivalent to ${ }^{5}$

$$
\max _{0 \leq \theta \leq 1} \theta\left[p_{\mathrm{h}}(1-\xi)-\frac{p_{\mathrm{h}}(1-\widehat{\theta}(1-\xi))\left(\xi-p_{\mathrm{h}}(2 \xi-1)\right)}{1-\widehat{\theta}\left(\xi-p_{\mathrm{h}}(2 \xi-1)\right)}\right] .
$$

Note that, since $\xi<1$ and $p_{\mathrm{h}}<1$, we must have $\xi-p_{\mathrm{h}}(2 \xi-1)>0$. Further, since $\xi \in\left(\frac{1}{2}, 1\right), p_{\mathrm{h}}>0$, and $\widehat{\theta} \in[0,1]$, we have that $1-\widehat{\theta}\left(\xi-p_{\mathrm{h}} \widehat{\theta}(2 \xi-1)\right)>1-\widehat{\theta} \xi+p_{\mathrm{h}} \widehat{\theta}>$ $1-\widehat{\theta} \xi>0$

\footnotetext{
${ }^{5}$ Note: $\xi-p_{\mathrm{h}}(2 \xi-1)=p_{\mathrm{h}}(1-\xi)+\left(1-p_{\mathrm{h}}\right) \xi$.
} 
Proposition 1 Social welfare $(\mathcal{W})$ is decreasing in the probability that the government agency sends a revealing signal.

Proof. The result follows from studying the sign inside the brackets in (20). The sign of this expression is always negative. Suppose it were nonnegative. Then, we would have

$$
p_{\mathrm{h}}(1-\xi) \geq \frac{p_{\mathrm{h}}(1-\widehat{\theta}(1-\xi))\left(\xi-p_{\mathrm{h}}(2 \xi-1)\right)}{1-\widehat{\theta} \xi+p_{\mathrm{h}} \widehat{\theta}(2 \xi-1)},
$$

implying that

$$
p_{\mathrm{h}}(1-\xi)-p_{\mathrm{h}}(1-\xi)\left(\xi-p_{\mathrm{h}}(2 \xi-1)\right) \widehat{\theta} \geq p_{\mathrm{h}}\left(\xi-p_{\mathrm{h}}(2 \xi-1)\right)-p_{\mathrm{h}}(1-\xi)\left(\xi-p_{\mathrm{h}}(2 \xi-1)\right) \widehat{\theta}
$$

The terms involving $\widehat{\theta}$ cancel out, and we have the condition

$$
p_{\mathrm{h}}(1-\xi)-p_{\mathrm{h}}\left(\xi-p_{\mathrm{h}}(2 \xi-1)\right) \geq 0 \text {. }
$$

This can be written as

$$
p_{\mathrm{h}}(2 \xi-1)\left(p_{\mathrm{h}}-1\right) \geq 0 .
$$

Since $0<p_{\mathrm{h}}<1$ and $\xi>\frac{1}{2}$, this is a contradiction, so the supposition must be false.

The intuition behind this result is that since we are considering a Lucas (1978) exchange economy, the agents consume the dividends from their endowed stocks in equilibrium. Thus, from the point of view of social welfare, releasing a revealing signal, the realization of which may be a signal about low growth (i.e. a low future dividend) can only be worse than releasing a manipulative high-growth signal.

An immediate corollary to the above is that in order to maximize social welfare, the government agency will send the manipulative high-growth signal $s_{M}=g_{\mathrm{h}}$ with probability one. 
Corollary 1 The solution to the government agency's problem is $\theta^{*}=0$. That is, with probability one, it will send the manipulative signal (lie), $s_{M}=g_{\mathrm{h}}$.

Note that, even if the agents hold beliefs that are consistent with the government's optimal strategy to send a manipulative signal, so that they assign a zero probability to a revealing signal, they still pay attention to the signal. That is, if the government agency signals a low growth rate, they realize that this signal must have come from $s_{R}$, and so they need to revise their beliefs accordingly (see item iv of Definition 1, which defines posterior beliefs following such a zero-probability event).

Even though social welfare is decreasing in the probability that the government agency releases a revealing signal as public information, there is a substantial positive value associated with receiving the revealing signal as private information. In the appendix, we analyze the optimal trading strategies and consumption of an agent with CRRA utility, who receives the revealing signal as private information, and we also quantify the value of this information by comparing his certainty-equivalent wealth to that of the uninformed case.

\section{Inattention and truth-telling}

In this section, we consider an economy where a positive measure of agents are inattentive and do not update their beliefs. We can think of these agents as having limited capacity to learn (Sims 2003, Van Nieuwerburgh and Veldkamp 2009). The other agents update their

beliefs in the same Bayesian manner and think that, with probability $\widehat{\theta}$ the government 
agency is sending the revealing signal $s_{R}$. The point is to show that the presence of those inattentive agents trigger, in some cases, truth-telling from the government.

We assume that the nonupdating agents have a mass of $v \in(0,1)$, so that the updating agents have a mass of $(1-v)$. The equilibrium concept that we considered in the benchmark model needs to be revised in order to accommodate nonupdating agents. However, because the necessary changes are straightforward, we do not state the revised equilibrium concept for the sake of brevity.

Since $g_{\mathrm{h}} \neq g_{\mathrm{l}}$, markets are complete, and we can solve for the equilibrium using two Arrow-Debreu (AD) securities: The first AD security delivers one unit of consumption if the growth rate turns out to be high $\left(g=g_{\mathrm{h}}\right)$ and zero units otherwise while the second AD security delivers one unit of consumption if the growth rate turns out to be low $\left(g=g_{1}\right)$ and zero units otherwise. The prices of these AD securities depend on the realization of the signal. We denote the price of the first $\mathrm{AD}$ security by $q_{\mathrm{h} j}$ and the price of the second one by $q_{1 j}$, where the index $j$ indicates the realization of the signal, where $j=\mathrm{h}$ in case of a high-growth signal and $j=\mathrm{l}$ in case of a low-growth signal.

We can write the nonupdating agents' problem as

$$
\begin{array}{r}
\max _{C_{2 j}^{v}, C_{3 \mathrm{~h} j}^{v}, C_{31 j}^{v}} u\left(C_{2 j}^{v}\right)+\beta\left[p_{\mathrm{h}} u\left(C_{3 \mathrm{~h} j}^{v}\right)+\left(1-p_{\mathrm{h}}\right) u\left(C_{31 j}^{v}\right)\right] \\
\text { s.t. } C_{2 j}^{v}+q_{\mathrm{h} j} C_{3 \mathrm{~h} j}^{v}+q_{\mathrm{l} j} C_{3 \mathrm{l} j}^{v}=D_{2}+q_{\mathrm{h} j} D_{2} g_{\mathrm{h}}+q_{\mathrm{lj}} D_{2} g_{1} \\
C_{2 j}^{v} \geq 0 \\
C_{3 \mathrm{~h} j}^{v} \geq 0 \\
C_{31 j}^{v} \geq 0
\end{array}
$$


Since $u^{\prime}(c) \rightarrow+\infty$ as $c \rightarrow 0$, the last three constraints are not binding. Hence, the corresponding Lagrangian is

$$
\begin{aligned}
\mathcal{L}_{j}=u\left(C_{2 j}^{v}\right)+\beta\left(p_{\mathrm{h}} u\left(C_{3 \mathrm{~h} j}^{v}\right)\right. & \left.+\left(1-p_{\mathrm{h}}\right) u\left(C_{3 \mathrm{l} j}^{v}\right)\right) \\
& +\lambda_{v j}\left(D_{2}+q_{\mathrm{h} j} D_{2} g_{\mathrm{h}}+q_{\mathrm{l} j} D_{2} g_{\mathrm{l}}-C_{2 j}^{v}-q_{\mathrm{h} j} C_{3 \mathrm{~h} j}^{v}-q_{\mathrm{l} j} C_{3 \mathrm{l} j}^{v}\right),
\end{aligned}
$$

where $\lambda_{v j}$ is the Lagrange multiplier. The first-order conditions with respect to initial and state-contingent consumption are

$$
\begin{array}{ll}
C_{2 j}^{v}: & u^{\prime}\left(C_{2 j}^{v}\right)-\lambda_{v j}=0, \\
C_{3 \mathrm{~h} j}^{v}: & \beta p_{\mathrm{h}} u^{\prime}\left(C_{3 \mathrm{~h} j}^{v}\right)-\lambda_{v j} q_{\mathrm{h} j}=0, \\
C_{3 \mathrm{l} j}^{v}: & \beta\left(1-p_{\mathrm{h}}\right) u^{\prime}\left(C_{3 \mathrm{~h} j}^{v}\right)-\lambda_{v j} q_{\mathrm{l} j}=0 .
\end{array}
$$

Assuming constant relative risk aversion, so that $u^{\prime}(c)=c^{-\gamma}$, we have that

$$
\begin{aligned}
C_{2 j}^{v} & =\lambda_{v j}^{-\frac{1}{\gamma}} \\
C_{3 \mathrm{~h} j}^{v} & =\left(\frac{\lambda_{v j} q_{\mathrm{h} j}}{\beta p_{\mathrm{h}}}\right)^{-\frac{1}{\gamma}}, \\
C_{31 j}^{v} & =\left(\frac{\lambda_{v j} q_{\mathrm{l} j}}{\beta\left(1-p_{\mathrm{h}}\right)}\right)^{-\frac{1}{\gamma}} .
\end{aligned}
$$

From the budget constraint, it follows that

$$
\lambda_{v j}^{-\frac{1}{\gamma}}=\frac{D_{2}\left(1+q_{\mathrm{h} j} g_{\mathrm{h}}+q_{\mathrm{lj}} g_{\mathrm{l}}\right)}{1+\beta^{\frac{1}{\gamma}}\left(p_{\mathrm{h}}^{\frac{1}{\gamma}} q_{\mathrm{h} j}^{1-\frac{1}{\gamma}}+\left(1-p_{\mathrm{h}}\right)^{\frac{1}{\gamma}} q_{\mathrm{l} j}^{1-\frac{1}{\gamma}}\right)} .
$$

We can use similar elementary lines to determine the optimal initial and state-contingent consumption of the updating agents. With those findings, we can now move to analyzing the government's optimal signal. 
Since our point is to identify a case where truth-telling becomes optimal, we solely focus on logarithmic utility functions $(\gamma=1)$; the same result obtains under more general assumptions. In this case, the initial and state-contingent consumption of the nonupdating agents looks as follows.

$$
\begin{aligned}
C_{2 j}^{v} & =\frac{D_{2}\left(1+q_{\mathrm{h} j} g_{\mathrm{h}}+q_{\mathrm{lj}} g_{\mathrm{l}}\right)}{1+\beta}, \\
C_{3 \mathrm{~h} j}^{v} & =\frac{\beta p_{\mathrm{h}}}{q_{\mathrm{h} j}} \frac{D_{2}\left(1+q_{\mathrm{h} j} g_{\mathrm{h}}+q_{\mathrm{lj}} g_{\mathrm{l}}\right)}{1+\beta}, \\
C_{3 \mathrm{l} j}^{v} & =\frac{\beta\left(1-p_{\mathrm{h}}\right)}{q_{\mathrm{l} j}} \frac{D_{2}\left(1+q_{\mathrm{h} j} g_{\mathrm{h}}+q_{\mathrm{lj}} g_{\mathrm{l}}\right)}{1+\beta} .
\end{aligned}
$$

Similarly, the consumption of the updating agents is given by

$$
\begin{aligned}
C_{2 j}^{u} & =\frac{D_{2}\left(1+q_{\mathrm{h} j} g_{\mathrm{h}}+q_{\mathrm{lj}} g_{\mathrm{l}}\right)}{1+\beta}, \\
C_{3 \mathrm{~h} j}^{u} & =\frac{\beta \widehat{\mu}_{\mathrm{h} j}}{q_{\mathrm{h} j}} \frac{D_{2}\left(1+q_{\mathrm{h} j} g_{\mathrm{h}}+q_{\mathrm{l} j} g_{\mathrm{l}}\right)}{1+\beta}, \\
C_{3 \mathrm{l} j}^{u} & =\frac{\beta\left(1-\widehat{\mu}_{\mathrm{h} j}\right)}{q_{\mathrm{l} j}} \frac{D_{2}\left(1+q_{\mathrm{h} j} g_{\mathrm{h}}+q_{\mathrm{l} j} g_{\mathrm{l}}\right)}{1+\beta} .
\end{aligned}
$$

The market-clearing conditions can be summarized as

$$
\begin{gathered}
v C_{2 j}^{v}+(1-v) C_{2 j}^{u}=D_{2}, \\
v C_{3 \mathrm{~h} j}^{v}+(1-v) C_{3 \mathrm{~h} j}^{u}=D_{2} g_{\mathrm{h}}, \\
v C_{3 \mathrm{l} j}^{v}+(1-v) C_{3 \mathrm{l} j}^{u}=D_{2} g_{\mathrm{l}},
\end{gathered}
$$

where, by Walras' law, market clearing in any two of these markets implies market clearing also in the third.

The first market-clearing condition in 40 can be rewritten as $q_{\mathrm{hj}} g_{\mathrm{h}}+q_{\mathrm{lj}} g_{\mathrm{l}}=\beta$. Thus, if we combine this with the second market clearing condition in (41), we obtain the prices 
of the AD securities;

$$
q_{\mathrm{h} j}=\frac{\beta\left(v p_{\mathrm{h}}+(1-v) \widehat{\mu}_{\mathrm{h} j}\right)}{g_{\mathrm{h}}}
$$

and

$$
q_{\mathrm{l} j}=\frac{\beta\left(1-v p_{\mathrm{h}}-(1-v) \widehat{\mu}_{\mathrm{h} j}\right)}{g_{\mathrm{l}}} .
$$

Here, we note that a stronger belief in a high growth rate among the updating agents (a higher $\widehat{\mu}_{\mathrm{h} j}$ ) leads to a higher price of consumption in the high-growth state and a lower price of consumption in the low-growth state.

The equilibrium consumption of the nonupdating agents is given by

$$
\begin{aligned}
C_{2 j}^{v} & =D_{2}, \\
C_{3 \mathrm{~h} j}^{v} & =\frac{p_{\mathrm{h}}}{v p_{\mathrm{h}}+(1-v) \widehat{\mu}_{\mathrm{h} j}} D_{2} g_{\mathrm{h}}, \\
C_{3 \mathrm{l} j}^{v} & =\frac{\left(1-p_{\mathrm{h}}\right)}{1-v p_{\mathrm{h}}-(1-v) \widehat{\mu}_{\mathrm{h} j}} D_{2} g_{\mathrm{l}},
\end{aligned}
$$

and, similarly, the updating agents' equilibrium consumption is

$$
\begin{aligned}
C_{2 j}^{u} & =D_{2}, \\
C_{3 \mathrm{~h} j}^{u} & =\frac{\widehat{\mu}_{\mathrm{h} j}}{v p_{\mathrm{h}}+(1-v) \widehat{\mu}_{\mathrm{h} j}} D_{2} g_{\mathrm{h}}, \\
C_{3 \mathrm{l} j}^{u} & =\frac{\left(1-\widehat{\mu}_{\mathrm{h} j}\right)}{1-v p_{\mathrm{h}}-(1-v) \widehat{\mu}_{\mathrm{h} j}} D_{2} g_{\mathrm{l}} .
\end{aligned}
$$

Thus, the ratios of state-contingent consumption equal the ratios of beliefs,

$$
\begin{aligned}
C_{3 \mathrm{~h} j}^{u} / C_{3 \mathrm{~h} j}^{v} & =\widehat{\mu}_{\mathrm{h} j} / p_{\mathrm{h}} \\
C_{3 \mathrm{l} j}^{u} / C_{3 \mathrm{l} j}^{v} & =\left(1-\widehat{\mu}_{\mathrm{h} j}\right) /\left(1-p_{\mathrm{h}}\right),
\end{aligned}
$$


meaning that, if the updating agents believe that a state is more likely than the nonupdating agents do, they will also allocate more resources to that state than the nonupdating agents. ${ }^{6}$

Suppose now that the government agency releases a high-growth signal. Then, assuming $\widehat{\theta}>0$, the updating agents would want to consume more in the high-growth state and less in the low-growth state than the nonupdating agents. Further, a higher fraction of nonupdating agents will decrease the price of consumption in the high-growth state and increase the price of consumption in the low-growth state. We can make a similar argument with opposite conclusions in case the government agency releases a low-growth signal.

The state-contingent consumptions of updating and nonupdating agents can be reached by trading the stock and the bond. Focusing on the updating agents, we can solve for their optimal asset holdings from

$$
\begin{aligned}
\phi_{j}^{u} D_{2} g_{\mathrm{h}}+\eta_{j}^{u} \cdot 1 & =C_{3 \mathrm{~h} j}^{u} \\
\phi_{j}^{u} D_{2} g_{\mathrm{l}}+\eta_{j}^{u} \cdot 1 & =C_{3 \mathrm{l} j}^{u},
\end{aligned}
$$

where $\phi_{j}^{u}$ is the number of stocks and $\eta_{j}^{u}$ is the number of bonds held by an updating agent. Solving for these holdings, we obtain the optimal number of stocks as

$$
\phi_{j}^{u}=\frac{\widehat{\mu}_{\mathrm{h} j}\left(1-\widehat{\mu}_{\mathrm{h} j}\right)\left(g_{\mathrm{h}}-g_{\mathrm{l}}\right)+v\left(\widehat{\mu}_{\mathrm{h} j}-p_{\mathrm{h}}\right)\left(\left(1-\widehat{\mu}_{\mathrm{h} j}\right) g_{\mathrm{l}}+\widehat{\mu}_{\mathrm{h} j} g_{\mathrm{h}}\right)}{\left(g_{\mathrm{h}}-g_{\mathrm{l}}\right)\left(v p_{\mathrm{h}}+(1-v) \widehat{\mu}_{\mathrm{h} j}\right)\left(1-v p_{\mathrm{h}}-(1-v) \widehat{\mu}_{\mathrm{h} j}\right)}
$$

\footnotetext{
${ }^{6}$ Note that they start out with identical endowments.
} 
and the optimal number of bonds as

$$
\eta_{j}^{u}=\frac{D_{2} g_{\mathrm{h}} g_{\mathrm{l}} v\left(p_{\mathrm{h}}-\widehat{\mu}_{\mathrm{h} j}\right)}{\left(g_{\mathrm{h}}-g_{\mathrm{l}}\right)\left(v p_{\mathrm{h}}+(1-v) \widehat{\mu}_{\mathrm{h} j}\right)\left(1-v p_{\mathrm{h}}-(1-v) \widehat{\mu}_{\mathrm{h} j}\right)} .
$$

Here, we can see that the updating agents will short sell the bond in order to invest more in the stock upon receiving a high-growth signal (provided that $v>0$ and $\widehat{\theta}>0$ ) because, in this case, they revise their belief regarding a high growth rate upwards $\left(\widehat{\mu}_{\mathrm{hh}}>p_{\mathrm{h}}\right)$. Upon receiving a low-growth signal, they will instead have a positive bond holding (provided that $v>0)$.

\subsection{Optimal asset holdings and inattentive agents}

We now analyze how the mass of nonupdating agents impact the overall distribution of bond and stock holdings. This issue is central to isolating cases where truth-telling becomes optimal.

We take the derivative of the updating agents' optimal bond holding with respect to $v$ :

$$
\frac{\partial \eta_{j}^{u}}{\partial v}=\frac{D_{2} g_{\mathrm{h}} g_{\mathrm{l}}\left(p_{\mathrm{h}}-\widehat{\mu}_{\mathrm{h} j}\right)\left(\left(1-\widehat{\mu}_{\mathrm{h} j}\right) \widehat{\mu}_{\mathrm{h} j}+\left(\widehat{\mu}_{\mathrm{h} j}-p_{\mathrm{h}}\right)^{2} v^{2}\right)}{\left(g_{\mathrm{h}}-g_{\mathrm{l}}\right)\left(v p_{\mathrm{h}}+(1-v) \widehat{\mu}_{\mathrm{h} j}\right)^{2}\left(1-v p_{\mathrm{h}}-(1-v) \widehat{\mu}_{\mathrm{h} j}\right)^{2}} .
$$

Hence, the sign of the derivative depends on the sign of $p_{\mathrm{h}}-\widehat{\mu}_{\mathrm{h} j}$, meaning that, conditional on a high-growth signal, the updating agents hold less of the bond the larger the mass of the nonupdating agents (provided that $\widehat{\theta}>0$ ). Similarly, conditional on a low-growth signal, the updating agents hold more of the bond the larger the mass of the updating agents. 
We can also study how the mass of the nonupdating agents affects the updating agents' optimal stock holding:

$$
\frac{\partial \phi_{j}^{u}}{\partial v}=\frac{\widehat{\mu}_{\mathrm{h} j}-p_{\mathrm{h}}}{g_{\mathrm{h}}-g_{\mathrm{l}}}\left(\frac{\widehat{\mu}_{\mathrm{h} j} g_{\mathrm{h}}}{\left(v p_{\mathrm{h}}+(1-v) \widehat{\mu}_{\mathrm{h} j}\right)^{2}}+\frac{\left(1-\widehat{\mu}_{\mathrm{h} j}\right) g_{\mathrm{l}}}{\left(1-v p_{\mathrm{h}}-(1-v) \widehat{\mu}_{\mathrm{h} j}\right)^{2}}\right) .
$$

That is, the sign of this derivative depends on the sign of $\widehat{\mu}_{\mathrm{h} j}-p_{\mathrm{h}}$. This is opposite the result we obtained regarding the updating agents' bond holdings. Thus, conditional on a high-growth signal, the updating agents hold more of the stock the larger the mass of the nonupdating agents (provided that $\widehat{\theta}>0$ ) and conditional on a low-growth signal, the updating agents hold less of the stock the larger the mass of the updating agents. Our interpretation of the above results is that the larger the mass of the nonupdating agents, the better are the updating agents' trading opportunities.

We next notice that the government's signal does not affect stock prices, while it directly affects holdings.

Lemma 3 In equilibrium, the stock price is independent of individual beliefs.

Proof. By no-arbitrage, the prices of the stock 7 and the bond are given by

$$
\begin{aligned}
& S_{j}=D_{2}\left(q_{\mathrm{h} j} g_{\mathrm{h}}+q_{\mathrm{l} j} g_{\mathrm{l}}\right)=\beta D_{2} \\
& B_{j}=q_{\mathrm{h} j}+q_{\mathrm{l} j}=\beta\left(\frac{\widehat{\mu}_{\mathrm{h} j}-v\left(\widehat{\mu}_{\mathrm{h} j}-p_{\mathrm{h}}\right)}{g_{\mathrm{h}}}+\frac{1-\widehat{\mu}_{\mathrm{h} j}+v\left(\widehat{\mu}_{\mathrm{h} j}-p_{\mathrm{h}}\right)}{g_{\mathrm{l}}}\right) .
\end{aligned}
$$

Here, we see that the stock price does not depend on beliefs. Hence, the government agency's signal does not affect the price of the risky asset.

\footnotetext{
${ }^{7}$ Note that the stock price is the price of a stock that has been stripped of its initial dividend.
} 
A quick look forward to 67) reveals that this result is specific for the log utility case. For risk aversions different from one, agents' beliefs and thus the government agency's signal will in general affect the stock price. However, the bond price will in general depend on beliefs also under log utility. We can consider the effect of a larger mass of nonupdating agents on the bond price:

$$
\frac{\partial B_{j}}{\partial v}=\beta\left(\frac{1}{g_{1}}-\frac{1}{g_{\mathrm{h}}}\right)\left(\widehat{\mu}_{\mathrm{h} j}-p_{\mathrm{h}}\right) .
$$

If the realized public signal is a signal about low growth $\left(s=g_{1}\right)$, a larger mass of nonupdating agents will lead to a lower bond price or, equivalently, a higher interest rate. This is because, in this case, the nonupdating agents are more optimistic regarding dividend growth than the updating agents $\left(\widehat{\mu}_{\mathrm{hl}}<p_{\mathrm{h}}\right)$. Thus, the bond is less attractive to the nonupdating agents, and the larger the mass of nonupdating agents, the lower the bond price. We can reason in a similar way in the case of a high-growth signal $\left(s=g_{\mathrm{h}}\right)$. Provided that the updating agents assign a nonzero probability to the possibility that the government agency sends a revealing signal $(\widehat{\theta}>0)$, the nonupdating agents are now more pessimistic regarding dividend growth than the updating agents $\left(\widehat{\mu}_{\mathrm{hh}}>p_{\mathrm{h}}\right)$, and so the bond seems more attractive in their eyes. Hence, as the mass of nonupdating agents increases, the equilibrium bond price has to increase, or equivalently, the interest rate must decrease. 


\subsection{Government's reaction with inattentive agents}

We now consider the problem of the government agency in this economy. As before, the agency seeks to maximize social welfare by choosing its probability of sending a revealing signal $(\theta)$. That is, it maximizes

$$
\begin{aligned}
& \mathcal{W}=v\left(\ln C_{2}^{v}+\beta[\right. \operatorname{Pr}\left(s=g_{\mathrm{h}}\right)\left(p_{\mathrm{h}} \ln C_{3 \mathrm{hh}}^{v}+\left(1-p_{\mathrm{h}}\right) \ln C_{3 \mathrm{~h}}^{v}\right) \\
&\left.\left.+\left(1-\operatorname{Pr}\left(s=g_{\mathrm{h}}\right)\right)\left(p_{\mathrm{h}} \ln C_{1 \mathrm{hl}}^{v}+\left(1-p_{\mathrm{h}}\right) \ln C_{11 \mathrm{l}}^{v}\right)\right]\right) \\
&+(1-v)\left(\ln C_{2}^{u}+\beta\left[\operatorname{Pr}\left(s=g_{\mathrm{h}}\right)\left(\widehat{\mu}_{\mathrm{hh}} \ln C_{3 \mathrm{hh}}^{u}+\left(1-\widehat{\mu}_{\mathrm{hh}}\right) \ln C_{3 \mathrm{lh}}^{u}\right)\right.\right. \\
&\left.\left.+\left(1-\operatorname{Pr}\left(s=g_{\mathrm{h}}\right)\right)\left(\widehat{\mu}_{\mathrm{hl}} \ln C_{3 \mathrm{hl}}^{u}+\left(1-\widehat{\mu}_{\mathrm{hl}}\right) \ln C_{3 \mathrm{ll}}^{u}\right)\right]\right),
\end{aligned}
$$

where $\operatorname{Pr}\left(s=g_{\mathrm{h}}\right)=1-\theta\left(\xi-p_{\mathrm{h}}(2 \xi-1)\right)$ is the probability of a high-growth signal from the perspective of the government agency. Note that $\xi-p_{\mathrm{h}}(2 \xi-1)=\left(1-p_{\mathrm{h}}\right) \xi+p_{\mathrm{h}}(1-\xi)>0$. Thus, the government agency's optimal policy depends on the sign of

$$
\begin{array}{r}
H \equiv v\left(p_{\mathrm{h}} \ln \left(\frac{\widehat{\mu}_{\mathrm{hh}}-v\left(\widehat{\mu}_{\mathrm{hh}}-p_{\mathrm{h}}\right)}{\widehat{\mu}_{\mathrm{hl}}-v\left(\widehat{\mu}_{\mathrm{hl}}-p_{\mathrm{h}}\right)}\right)+\left(1-p_{\mathrm{h}}\right) \ln \left(\frac{1-\widehat{\mu}_{\mathrm{hh}}+v\left(\widehat{\mu}_{\mathrm{hh}}-p_{\mathrm{h}}\right)}{1-\widehat{\mu}_{\mathrm{hl}}+v\left(\widehat{\mu}_{\mathrm{hl}}-p_{\mathrm{h}}\right)}\right)\right) \\
-(1-v)\left(\widehat{\mu}_{\mathrm{hh}} \ln \left(\frac{\widehat{\mu}_{\mathrm{hh}} g_{\mathrm{h}}}{\widehat{\mu}_{\mathrm{hh}}-v\left(\widehat{\mu}_{\mathrm{hh}}-p_{\mathrm{h}}\right)}\right)+\left(1-\widehat{\mu}_{\mathrm{hh}}\right) \ln \left(\frac{\left(1-\widehat{\mu}_{\mathrm{hh}}\right) g_{\mathrm{l}}}{1-\widehat{\mu}_{\mathrm{hh}}+v\left(\widehat{\mu}_{\mathrm{hh}}-p_{\mathrm{h}}\right)}\right)\right. \\
\left.-\widehat{\mu}_{\mathrm{hl}} \ln \left(\frac{\widehat{\mu}_{\mathrm{hl}} g_{\mathrm{h}}}{\widehat{\widehat{\mu}}_{\mathrm{hl}}-v\left(\widehat{\mu}_{\mathrm{hl}}-p_{\mathrm{h}}\right)}\right)-\left(1-\widehat{\mu}_{\mathrm{hl}}\right) \ln \left(\frac{\left(1-\widehat{\mu}_{\mathrm{hl}}\right) g_{\mathrm{l}}}{1-\widehat{\mu}_{\mathrm{hl}}+v\left(\widehat{\mu}_{\mathrm{hl}}-p_{\mathrm{h}}\right)}\right)\right) .
\end{array}
$$

If (63) is positive, then social welfare is increasing in the probability of a revealing signal, and the government agency's optimal policy is to send a revealing signal with probability one $\left(\theta^{*}=1\right)$. If the above expression is negative, the optimal policy is to send a manipulative signal (lie) with probability one $\left(\theta^{*}=0\right)$, and if the above expression is zero, then the optimal solution is $\theta^{*} \in[0,1]$. Simple numerical tests show that the sets of parameters 
generating positive, negative and zero values on $H$ are all nonempty. Thus, unlike the case under homogeneous beliefs, social welfare can increase with the probability that the government agency sends a revealing signal.

In Figure 1, we plot the value of $H$ as a function of the mass of nonupdating agents $(v)$ for a particular set of parameter values. The figure shows that if the mass of nonupdating agents $(v)$ is sufficiently large, it is optimal for the government agency to send the revealing signal with probability one 8 However, if the mass of nonupdating agents is small, it is instead optimal for the government agency to send the manipulative signal (lie) with probability one.$^{9}$ This is because, with a larger mass of nonupdating agents, the updating agents are able to make better trades based on the revealing signal and this effect dominates the adverse effect that the revealing signal has on the nonupdating agents' expected utility.

\section{Conclusion}

This paper analyzes how a benevolent government agency would optimally convey information regarding future growth rates and the effects of this information on agents'

\footnotetext{
${ }^{8}$ We have chosen $\widehat{\theta}=0.5$ for illustrative purposes. The result that it can be optimal for the government agency to send the revealing signal with probability one also holds when the beliefs of the updating agents are consistent with the government agency's strategy, when $\widehat{\theta}=1$.

${ }^{9}$ The result that it can be optimal for the government agency to send the manipulative signal (lie) with probability one also holds when the beliefs of the updating agents are consistent with the government agency's strategy, when $\widehat{\theta}=0$.
} 
strategies and equilibrium asset prices. The government agency chooses between releasing a revealing signal that partially reveals the true future growth rate and a manipulative signal (lie) according to which the future growth rate is "high."

We find that if all agents start out with identical priors and update their beliefs, then it is optimal for the government agency to release the manipulative signal (lie) with probability one. However, if some agents are inattentive and do not update their beliefs, it can in fact be optimal for the government agency to release the revealing signal with probability one. This occurs because the updating agents can benefit from the information contained in the public signal when trading with the nonupdating agents, and this effect dominates the adverse effect that it has on the expected utility of nonupdating agents.

We study the effects of the nonupdating agents on the updating agents' optimal strategies and asset prices. Increasing the mass of the nonupdating agents accentuates the updating agents' response to signal realizations. Conditional on a low-growth signal, a larger mass of nonupdating agents increases the updating agents' bond holdings, while it decreases their stock holdings. Provided that the updating agents assign a nonzero probability to the possibility of a revealing signal, the effects conditional on a high-growth signal are the opposite. We also find that the nonupdating agents increase (decrease) the interest rate conditional on a low(high)-growth signal, where the result regarding the high-growth signal again requires that the updating agents assign a nonzero probability to the possibility that the government agency sends a revealing signal.

For tractability, we restrict our attention to logarithmic utility when considering the effects of inattentive agents. We also model inattention in the simplest possible way, 
assuming that, for reasons that lie outside our framework, the inattentive agents ignore the public signal. A recent vein of the literature endogenously models inattention as a rational decision under capacity constraints (e.g., Sims 2003, Van Nieuwerburgh and Veldkamp 2009). Studying the effects of inattention in a more general setting where relative risk aversions are different from one and endogenizing inattention (particularly when there are several sources of information) constitute possible avenues for future research.

\section{Appendix}

\section{A The private value of a revealing signal}

In spite of the fact that, assuming that all agents are updating, social welfare is decreasing in the probability that the government agency releases a revealing signal as public information, there is a substantial positive value associated with receiving the revealing signal as private information. In this section, we consider a small investor (small enough not to affect prices ${ }^{10}$ who receives $s_{R}$ as private information and knows that he receives this signal and not $s_{M}$, while all other agents just observe the government agency's signal. We study his optimal consumption and portfolio choice and investigate the economic value of receiving this signal as private information. For simplicity, we consider the case of

\footnotetext{
${ }^{10}$ We note that this assumption is in line with the general setting of the model in that there is a continuum of agents, with each agent having a mass of zero.
} 
constant relative risk aversion (CRRA),

$$
u(c)=\left\{\begin{array}{l}
\frac{c^{1-\gamma}}{1-\gamma} \text { if } \gamma>0, \gamma \neq 1, \\
\ln c \text { if } \gamma=1
\end{array}\right.
$$

An agent who has access to the revealing signal and knows it will have the following posterior beliefs.

$$
\begin{aligned}
& \bar{\mu}_{\mathrm{hh}} \equiv \overline{\operatorname{Pr}}\left(g=g_{\mathrm{h}} \mid s_{R}, s=g_{\mathrm{h}}\right)=\frac{p_{\mathrm{h}} \xi}{1-\xi+p_{\mathrm{h}}(2 \xi-1)} \\
& \bar{\mu}_{\mathrm{hl}} \equiv \overline{\operatorname{Pr}}\left(g=g_{\mathrm{h}} \mid s_{R}, s=g_{\mathrm{l}}\right)=\frac{p_{\mathrm{h}}(1-\xi)}{p_{\mathrm{h}}(1-\xi)+\left(1-p_{\mathrm{h}}\right) \xi}
\end{aligned}
$$

Denoting the corresponding posterior distributions of the "general population" by $\widehat{\mu}_{\mathrm{hh}}$ and $\widehat{\mu}_{\mathrm{hl}}$, we have that the price of the stock is: 11

$$
S=S_{\mathrm{h}}=\beta D_{2}\left(\widehat{\mu}_{\mathrm{hh}} g_{\mathrm{h}}^{1-\gamma}+\left(1-\widehat{\mu}_{\mathrm{hh}}\right) g_{\mathrm{l}}^{1-\gamma}\right)
$$

and the price of the bond is given by

$$
B=B_{\mathrm{h}}=\beta\left(\widehat{\mu}_{\mathrm{hh}} g_{\mathrm{h}}^{-\gamma}+\left(1-\widehat{\mu}_{\mathrm{hh}}\right) g_{\mathrm{l}}^{-\gamma}\right)
$$

In what follows, we assume that the "general population" has realized that the government agency will only send manipulative signals and hold beliefs that are consistent with this view. That is, we assume that $\widehat{\theta}=0$, so that $\widehat{\mu}_{\mathrm{hh}}=p_{\mathrm{h}}$. In this case

$$
S=\beta D_{2}\left(p_{\mathrm{h}} g_{\mathrm{h}}^{1-\gamma}+\left(1-p_{\mathrm{h}}\right) g_{\mathrm{l}}^{1-\gamma}\right)
$$

and

$$
B=\beta\left(p_{\mathrm{h}} g_{\mathrm{h}}^{-\gamma}+\left(1-p_{\mathrm{h}}\right) g_{\mathrm{l}}^{-\gamma}\right) .
$$

\footnotetext{
${ }^{11}$ Note that the general population will only receive high-growth signals. Therefore, $\widehat{\mu}_{\mathrm{hh}}$ is the only relevant posterior in this case.
} 
The first-order conditions for the agent having access to the revealing signal are given by

$$
\begin{gathered}
C_{2}^{-\gamma}-\frac{1}{B} \beta\left(\bar{\mu}_{\mathrm{h} j}\left(\phi D_{2} g_{\mathrm{h}}+\frac{S+D_{2}-\phi S-C_{2}}{B}\right)^{-\gamma}\right. \\
\left.+\left(1-\bar{\mu}_{\mathrm{h} j}\right)\left(\phi D_{2} g_{\mathrm{l}}+\frac{S+D_{2}-\phi S-C_{2}}{B}\right)^{-\gamma}\right)=0 \quad(j=\mathrm{h}, \mathrm{l}) \\
\bar{\mu}_{\mathrm{h} j}\left(D_{2} g_{\mathrm{h}}-\frac{S}{B}\right)\left(\phi D_{2} g_{\mathrm{h}}+\frac{S+D_{2}-\phi S-C_{2}}{B}\right)^{-\gamma} \\
+\left(1-\bar{\mu}_{\mathrm{h} j}\right)\left(D_{2} g_{\mathrm{l}}-\frac{S}{B}\right)\left(\phi D_{2} g_{1}+\frac{S+D_{2}-\phi S-C_{2}}{B}\right)^{-\gamma}=0 \quad(j=\mathrm{h}, \mathrm{l})
\end{gathered}
$$

In Table 1, we show numerical results for different levels of relative risk aversion, assuming that $p_{\mathrm{h}}=0.6, \xi=0.8, g_{\mathrm{h}}=1.2, g_{\mathrm{l}}=0.8, \beta=0.95$ and $D_{2}=1$. We compute optimal initial consumption $\left(C_{2}\right)$ and stock holdings $(\phi)$, together with expected utility $(E U)$, certainty-equivalent wealth $(C E W)$ and difference in certainty-equivalent wealth compared to the uninformed case $(\triangle C E W)$ for the case of both a high-growth signal $\left(s_{R}=g_{\mathrm{h}}\right)$ and a low-growth signal $\left(s_{R}=g_{\mathrm{l}}\right)$. We also report the overall (unconditional) expected utility together with certainty-equivalent wealth and difference in certaintyequivalent wealth compared to the uninformed case. We note that the gains of receiving the revealing signal in terms of certainty-equivalent wealth are substantial for almost all levels of risk aversion (the only exception being the case of quadratic utility, $\gamma=2$ ), with values of $\triangle C E W$ ranging from $0.7 \%$ to $295 \%$ of the initial dividend value and most values being around $20 \%$ to $40 \%$ of the initial dividend value.

Upon receiving a high-growth signal $\left(s_{R}=g_{\mathrm{h}}\right)$, the privately informed agent invests more in the stock than the uninformed agents. Receiving a high-growth signal has two 
effects on his optimal consumption: The first effect is a wealth effect (because of the higher expected return, he is "richer" and can consume more); the second effect is a substitution effect (because of the higher expected return, he wants to invest more in the stock and consume less). For an agent with a risk aversion less than one, the substitution effect dominates, whereas, for an agent with a risk aversion that is higher than one, the wealth effect dominates. For a $\log$ utility $(\gamma=1)$ agent, the two effects cancel out, and he thus consumes just as much as the uninformed agents.

Upon receiving a low-quality signal $\left(s_{R}=g_{1}\right)$, the privately informed agent invests less in the stock than the uninformed agents. As seen in Table 1, for levels of relative risk aversion of three or less, the privately informed agent will even short sell the stock. In the case of $\log$ utility $(\gamma=1)$ and especially in the square-root case $(\gamma=0.5)$, the short selling is substantial. This short selling is due to the fact that for these levels of risk aversion, the expected return on the stock from the point of view of the privately informed agent is lower than the interest rate ${ }^{12}$ In the case when the expected return is higher than the interest rate, the substitution effect is positive (he substitutes investments for consumption), whereas the wealth effect is negative (he is poorer). In the case when the expected return on the stock is lower than the interest rate, the wealth effect is positive (he is richer and wants to consume more), whereas the substitution effect is ambiguous because of the short selling.

\footnotetext{
${ }^{12}$ Note that agents share the same coefficient of relative risk aversion $(\gamma)$.
} 


\section{B Proof of Lemma 2}

By Bayes' Theorem, we have that

$$
\begin{aligned}
& \widehat{\operatorname{Pr}}\left(g=g_{\mathrm{h}} \mid s=g_{\mathrm{h}}\right)= \\
& \frac{\widehat{\operatorname{Pr}}\left(g=g_{\mathrm{h}}\right) \widehat{\operatorname{Pr}}\left(s=g_{\mathrm{h}} \mid g=g_{\mathrm{h}}\right)}{\widehat{\operatorname{Pr}}\left(g=g_{\mathrm{h}}\right) \widehat{\operatorname{Pr}}\left(s=g_{\mathrm{h}} \mid g=g_{\mathrm{h}}\right)+\left(1-\widehat{\operatorname{Pr}}\left(g=g_{\mathrm{h}}\right)\right) \widehat{\operatorname{Pr}}\left(s=g_{\mathrm{h}} \mid g=g_{\mathrm{l}}\right)} .
\end{aligned}
$$

Further, by the law of total probability,

$$
\begin{aligned}
\widehat{\operatorname{Pr}}\left(s=g_{\mathrm{h}} \mid g=g_{\mathrm{h}}\right)= & \widehat{\operatorname{Pr}}\left(s_{R}\right) \widehat{\operatorname{Pr}}\left(s=g_{\mathrm{h}} \mid s_{R}, g=g_{\mathrm{h}}\right) \\
& +\left(1-\widehat{\operatorname{Pr}}\left(s_{R}\right)\right) \widehat{\operatorname{Pr}}\left(s=g_{\mathrm{h}} \mid s_{M}, g=g_{\mathrm{h}}\right) \\
= & \widehat{\theta} \xi+(1-\widehat{\theta}) \cdot 1=1-\widehat{\theta}(1-\xi) .
\end{aligned}
$$

Similarly, we have that

$$
\begin{aligned}
\widehat{\operatorname{Pr}}\left(s=g_{\mathrm{h}} \mid g=g_{\mathrm{l}}\right)= & \widehat{\operatorname{Pr}}\left(s_{R}\right) \widehat{\operatorname{Pr}}\left(s=g_{\mathrm{h}} \mid s_{R}, g=g_{\mathrm{l}}\right) \\
& +\left(1-\widehat{\operatorname{Pr}}\left(s_{R}\right)\right) \widehat{\operatorname{Pr}}\left(s=g_{\mathrm{h}} \mid s_{M}, g=g_{\mathrm{l}}\right) \\
= & \widehat{\theta}(1-\xi)+(1-\widehat{\theta}) \cdot 1=1-\widehat{\theta} \xi .
\end{aligned}
$$

Simplifying, we obtain the following expression for the probability of a high growth rate conditional on a high-growth signal.

$$
\widehat{\operatorname{Pr}}\left(g=g_{\mathrm{h}} \mid s=g_{\mathrm{h}}\right)=\frac{p_{\mathrm{h}}(1-\widehat{\theta}(1-\xi))}{1-\widehat{\theta} \xi+p_{\mathrm{h}} \widehat{\theta}(2 \xi-1)}
$$


Also, by Bayes' Theorem, the probability of a high growth rate conditional on a lowgrowth signal is given by

$$
\begin{aligned}
& \widehat{\operatorname{Pr}}\left(g=g_{\mathrm{h}} \mid s=g_{\mathrm{l}}\right)= \\
& \widehat{\widehat{\operatorname{Pr}}\left(g=g_{\mathrm{h}}\right) \widehat{\operatorname{Pr}}\left(s=g_{\mathrm{l}} \mid g=g_{\mathrm{h}}\right)+\left(1-\widehat{\operatorname{Pr}}\left(g=g_{\mathrm{h}}\right)\right) \widehat{\operatorname{Pr}}\left(s=g_{\mathrm{l}} \mid g=g_{\mathrm{l}}\right)} .
\end{aligned}
$$

The probability of a low-growth signal conditional on a high growth rate can be obtained by the law of total probability,

$$
\begin{aligned}
\widehat{\operatorname{Pr}}\left(s=g_{\mathrm{l}} \mid g=g_{\mathrm{h}}\right)= & \widehat{\operatorname{Pr}}\left(s_{R}\right) \widehat{\operatorname{Pr}}\left(s=g_{\mathrm{l}} \mid s_{R}, g=g_{\mathrm{h}}\right) \\
& +\left(1-\widehat{\operatorname{Pr}}\left(s_{R}\right)\right) \widehat{\operatorname{Pr}}\left(s=g_{\mathrm{l}} \mid s_{M}, g=g_{\mathrm{h}}\right) \\
= & \widehat{\theta}(1-\xi)+(1-\widehat{\theta}) \cdot 0=\widehat{\theta}(1-\xi) .
\end{aligned}
$$

In a similar manner, the probability of a low-growth signal conditional on a low growth rate can be obtained as

$$
\begin{aligned}
\widehat{\operatorname{Pr}}\left(s=g_{1} \mid g=g_{1}\right)= & \widehat{\operatorname{Pr}}\left(s_{R}\right) \widehat{\operatorname{Pr}}\left(s=g_{1} \mid s_{R}, g=g_{1}\right) \\
& +\left(1-\widehat{\operatorname{Pr}}\left(s_{R}\right)\right) \widehat{\operatorname{Pr}}\left(s=g_{1} \mid s_{M}, g=g_{1}\right) \\
= & \widehat{\theta} \xi+(1-\widehat{\theta}) \cdot 0=\widehat{\theta} \xi .
\end{aligned}
$$

Thus, the probability of a high growth rate conditional on a low-growth signal is given by

$$
\begin{aligned}
\widehat{\operatorname{Pr}}\left(g=g_{\mathrm{h}} \mid s=g_{\mathrm{l}}\right) & =\frac{p_{\mathrm{h}} \widehat{\theta}(1-\xi)}{p_{\mathrm{h}} \widehat{\theta}(1-\xi)+\left(1-p_{\mathrm{h}}\right) \widehat{\theta} \xi} \\
& =\frac{p_{\mathrm{h}}(1-\xi)}{p_{\mathrm{h}}(1-\xi)+\left(1-p_{\mathrm{h}}\right) \xi} \quad(\widehat{\theta} \neq 0) .
\end{aligned}
$$


If $\widehat{\theta}=0$ and agents observe $s=g_{1}$, they revise their beliefs (since $s=g_{1}$ must have come from $s_{R}$ ), so that also in this case their posterior is given by the expression in 81 . 13

${ }^{13}$ Note that this is the limiting posterior as $\widehat{\theta} \rightarrow 0$. 


\section{References}

AshiYA, M. (2007): "Forecast Accuracy of the Japanese Government: Its Year-Ahead GDP Forecast is Too Optimistic," Japan and the World Economy, 19, 68-85.

Boylan, R. T. (2008): "Political Distortions in State Forecasts," Public Choice, 136, $411-427$.

Campbell, C. M. (2004): "Blackwell's Ordering and Public Information," Journal of Economic Theory, 114, 179-197.

Cohen, L., And A. Frazzini (2008): "Economic Links and Predictable Returns," Journal of Finance, 63, 1977-2011.

Crawford, V. P., And J. Sobel (1982): "Strategic Information Transmission," Econometrica, 50, 1431-1451.

DellaVigna, S., and J. Pollet (2006): "Investor Inattention, Firm Reaction, and Friday Earnings Announcements," NBER Working Paper No. 11683.

Drèze, J. H. (1960): "Le Paradoxe de l'Information," Economie Appliquée, 13, 71-80.

Economist (2004): "It's Not Always Good to Talk," July 22, 2004, Issue No. 71.

Feldman, D. (2004): "Separating Signaling Equilibria under Random Relations between Costs and Attributes: Discrete Attributes," Mathematical Social Sciences, 48, 93-101. 
Feldman, D., and R. S. Winer (2004): "Separating Signaling Equilibria under Random Relations between Costs and Attributes: Continuum of Attributes," Mathematical Social Sciences, 48, 81-91.

Green, J. (1981): "Value of Information with Sequential Futures Markets," Econometrica, 49, 335-358.

Hakansson, N., G. Kunkel, and J. Ohlson (1982): "Sufficient and Necessary Conditions for Information to have Social Value in Pure Exchange," Journal of Finance, $37,1169-1181$.

Hirshleifer, D. A., S. S. Lim, and S. H. Teoh (2009): "Driven to Distraction: Extraneous Events and Underreaction to Earnings News," Journal of Finance, 64, $2289-2325$.

Hirshleifer, J. (1971): "The Private and Social Value of Information and the Reward to Inventive Activity," American Economic Review, 61, 561-574.

Huberman, G., And T. Regev (2001): "Contagious Speculation and a Cure for Cancer: A Nonevent that Made Stock Prices Soar," Journal of Finance, 56, 387-396.

Jonung, L., And M. Larch (2006): "Improving Fiscal Policy in the EU: The Case for Independent Forecasts," Economic Policy, 21, 493-534.

Keynes, J. M. (1936): The General Theory of Employment, Interest, and Money. MacMillan, London. 
LAFFont, J.-J. (1991): Economie de l'Incertain et de l'Information, Vol. 2. Economica, Paris.

LucAs, JR., R. E. (1978): "Asset Prices in an Exchange Economy," Econometrica, 46, $1429-1445$.

Marshall, J. M. (1974): "Private Incentives and Public Information," American Economic Review, 64, 373-390.

Morris, S., And H. S. Shin (2002): "The Social Value of Public Information," American Economic Review, 92, 1521-1534.

Morris, S., H. S. Shin, And H. Tong (2006): "Response to 'The Social Value of Public Information: Morris and Shin (2002) is Actually Pro Transparency, Not Con'," American Economic Review, 96, 453-455.

NG, D. (1975): "Information Accuracy and Social Welfare under Homogeneous Beliefs," Journal of Financial Economics, 2, 53-70.

Riley, J. G. (1975): "Competitive Signalling," Journal of Economic Theory, 10, 174186.

(2001): "Silver Signals: Twenty-Five Years of Screening and Signaling," Journal of Economic Literature, 39, 432-478.

SchleE, E. (2001): "The Value of Information in Efficient Risk-Sharing Arrangements," American Economic Review, 91, 509-524. 
Sims, C. A. (2003): "Implications of Rational Inattention," Journal of Monetary Economics, 50, 665-690.

Spence, A. M. (1973): "Job Market Signaling," Quarterly Journal of Economics, 87, $355-374$.

Svensson, L. E. O. (2006): "The Social Value of Public Information: Morris and Shin (2002) is Actually Pro Transparency, Not Con," American Economic Review, 96, 448452.

Van Nieuwerburgh, S., and L. Veldkamp (2009): "Information Immobility and the Home Bias Puzzle," Journal of Finance, 64, 1187-1215. 
Table 1: The table shows the privately informed agent's optimal initial consumption and stock holding for different levels of risk aversion $(\gamma)$. We also calculate his expected utility $(E U)$, certainty-equivalent wealth $(C E W)$ and the difference in certainty-equivalent wealth as compared to the uninformed case $(\triangle C E W)$. We have assumed the following parameter values: $\beta=0.95, D_{2}=1, g_{\mathrm{h}}=1.2, g_{\mathrm{l}}=0.8, p_{\mathrm{h}}=0.6$, and $\xi=0.8$.

\begin{tabular}{llllll}
\multicolumn{6}{c}{$s_{R}=g_{\mathrm{h}}$} \\
\hline & \multicolumn{1}{c}{$C_{2}$} & \multicolumn{1}{c}{$E U$} & \multicolumn{1}{c}{$C E W$} & $\Delta C E W$ \\
\hline$\gamma=0.5$ & 0.84754 & 4.9728 & 4.2673 & 4.5525 & 2.9522 \\
$\gamma=1$ & 1.0000 & 3.5714 & 0.26888 & 1.3085 & 0.28918 \\
$\gamma=2$ & 1.0531 & 2.5175 & -1.7582 & 0.56877 & 0.06878 \\
$\gamma=3$ & 1.0656 & 2.0884 & -0.8221 & 0.77987 & 0.33451 \\
$\gamma=4$ & 1.0712 & 1.8571 & -0.52462 & 0.8597 & 0.39751 \\
$\gamma=5$ & 1.0743 & 1.7125 & -0.38482 & 0.89778 & 0.40721 \\
$\gamma=6$ & 1.0761 & 1.6131 & -0.30775 & 0.91742 & 0.39805 \\
$\gamma=7$ & 1.0768 & 1.5402 & -0.26219 & 0.92727 & 0.38123 \\
$\gamma=8$ & 1.0767 & 1.4840 & -0.23505 & 0.93134 & 0.36121 \\
$\gamma=9$ & 1.0758 & 1.4389 & -0.21997 & 0.93179 & 0.34005 \\
$\gamma=10$ & 1.0744 & 1.4017 & -0.21367 & 0.92992 & 0.31879 \\
\hline
\end{tabular}

\begin{tabular}{llrlll}
\multicolumn{6}{c}{$s_{R}=g_{1}$} \\
\hline & \multicolumn{1}{c}{$C_{2}$} & $\phi$ & \multicolumn{1}{c}{$E U$} & \multicolumn{1}{c}{$C E W$} & $\Delta C E W$ \\
\hline$\gamma=0.5$ & 0.87201 & -5.2249 & 4.207 & 4.4247 & 2.8244 \\
$\gamma=1$ & 1.0000 & -2.2727 & 0.10184 & 1.1072 & 0.08789 \\
$\gamma=2$ & 0.99453 & -0.67051 & -1.9715 & 0.50722 & 0.00722 \\
$\gamma=3$ & 0.98056 & -0.13179 & -1.0551 & 0.68838 & 0.24302 \\
$\gamma=4$ & 0.97157 & 0.13687 & -0.77514 & 0.75480 & 0.29261 \\
$\gamma=5$ & 0.96591 & 0.29781 & -0.65492 & 0.78602 & 0.29546 \\
$\gamma=6$ & 0.96241 & 0.40521 & -0.60122 & 0.80242 & 0.28305 \\
$\gamma=7$ & 0.96039 & 0.48222 & -0.58399 & 0.81141 & 0.26537 \\
$\gamma=8$ & 0.95942 & 0.54039 & -0.59121 & 0.81636 & 0.24623 \\
$\gamma=9$ & 0.95922 & 0.58608 & -0.61775 & 0.81896 & 0.22722 \\
$\gamma=10$ & 0.95958 & 0.62309 & -0.66167 & 0.82017 & 0.20903 \\
\hline
\end{tabular}

\begin{tabular}{lccl} 
& \multicolumn{2}{c}{ Overall } \\
\hline & $E U$ & $C E W$ & $\Delta C E W$ \\
\hline$\gamma=0.5$ & 4.2408 & 4.4961 & 2.8957 \\
$\gamma=1$ & 0.19538 & 1.2158 & 0.19646 \\
$\gamma=2$ & -1.8521 & 0.53994 & 0.03994 \\
$\gamma=3$ & -0.92464 & 0.73536 & 0.29000 \\
$\gamma=4$ & -0.63485 & 0.80674 & 0.34456 \\
$\gamma=5$ & -0.50366 & 0.83936 & 0.34879 \\
$\gamma=6$ & -0.43687 & 0.85533 & 0.33596 \\
$\gamma=7$ & -0.40378 & 0.86288 & 0.31684 \\
$\gamma=8$ & -0.39176 & 0.86579 & 0.29557 \\
$\gamma=9$ & -0.39500 & 0.86604 & 0.27431 \\
$\gamma=10$ & -0.41079 & 0.86478 & 0.25365 \\
\hline
\end{tabular}




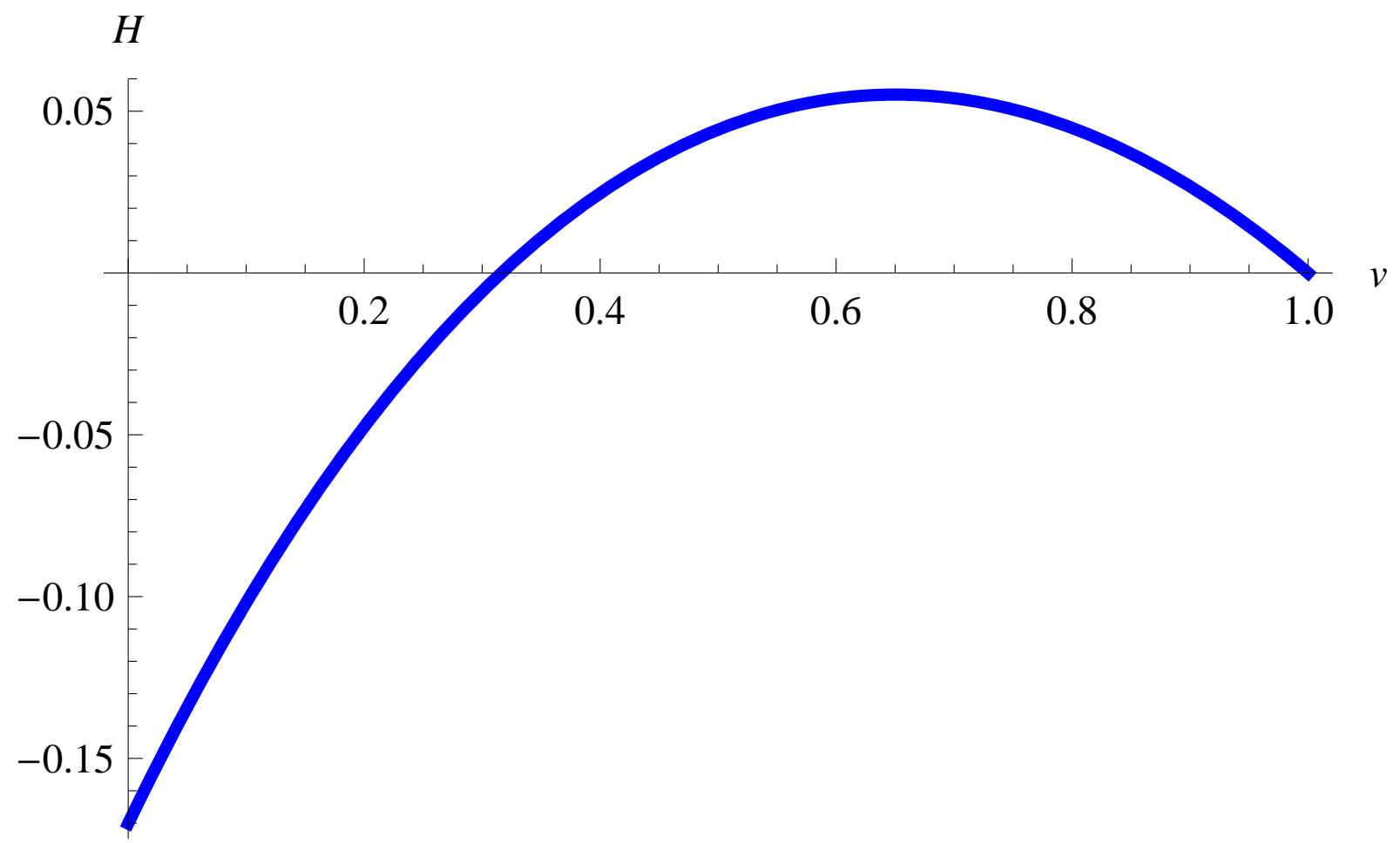

Figure 1: The figure shows $H$ in (63) as a function of the mass of the nonupdating agents $(v)$. A positive (negative) value means that social welfare is increasing (decreasing) in the probability that the government agency sends a revealing signal $(\theta)$. We have assumed the following parameter values: $g_{\mathrm{h}}=1.2, g_{\mathrm{l}}=0.8, p_{\mathrm{h}}=0.6, \xi=0.8$ and $\widehat{\theta}=0.5$. 